\title{
Abdominal compartment syndrome
}

\section{Manu Malbrain}

Address: ZNA Stuivenberg, Lange Beeldekensstraat 267, B-2060 Antwerpen 6, Belgium

Email: manu.malbrain@skynet.be

FI000 Medicine Reports 2009, I:86 (doi:10.3410/MI-86)

The electronic version of this article is the complete one and can be found at: http://FI000.com/Reports/Medicine/content///86

\begin{abstract}
The abdominal compartment syndrome (ACS) was first described in surgical patients with abdominal aortic aneurysm repair, trauma, bleeding, or infection, but in recent years it has also been described in patients with other pathologies such as burn injury and sepsis and in medical patients. This FI000 Medicine Report is intended to provide critical care physicians a clear insight into the current state of knowledge regarding intra-abdominal hypertension (IAH) and ACS, and will focus primarily on the recent literature as well as on the definitions and recommendations published by the World Society of the Abdominal Compartment Syndrome. The definitions regarding increased intraabdominal pressure (IAP) will be listed, followed by a brief but comprehensive overview of the different mechanisms of organ dysfunction associated with IAH. The gold standard measurement technique for IAP as well as recommendations for organ function support in patients with IAH and options for medical and surgical treatment of IAH and ACS will be discussed.
\end{abstract}

\section{Introduction and context}

A compartment syndrome exists when the increased pressure in a closed anatomic space threatens the viability of surrounding tissue. When this occurs in the abdomen, the impact on end-organ function within and outside the cavity can be devastating. The abdominal compartment syndrome (ACS) is not a disease; as such, it can have many causes and can develop within many disease processes. It is only recently that ACS has received heightened attention [1]. The prevention of intra-abdominal hypertension (IAH) and ACS is of tremendous importance in the care of critically ill, surgical, and trauma patients. Serial intra-abdominal pressure (IAP) measurements are essential to the diagnosis, management, and fluid resuscitation of these patients. Clinical examination is not an accurate method to estimate IAP [2]. Intravesicular pressure is a good estimate for IAP, is easily measured, and should be monitored in all patients believed to be at risk for significant elevations in IAP [3-6].

The management of IAH is based on four principles [3-6] (Figure 1): (a) serial monitoring of IAP; (b) optimization of systemic perfusion and organ function in the patient with elevated IAP; (c) institution of specific medical procedures to reduce IAP and the end-organ consequences of IAH/ACS; (d) prompt surgical decompression for refractory IAH.

\section{Recent advances}

Recently, the World Society of the Abdominal Compartment Syndrome (WSACS) [7] published the consensus definitions and recommendations regarding the diagnosis and management of IAH and ACS $[4,5]$.

\section{Consensus definitions}

Intra-abdominal pressure: IAP is the steady-state pressure concealed within the abdominal cavity. It is directly affected by the volume of the solid organs or hollow viscera (which may be either empty or filled with air, liquid, or fecal matter), the presence of ascites, blood or other space-occupying lesions (such as tumors or a gravid uterus), and the presence of conditions that limit expansion of the abdominal wall (such as burn eschars or third-space edema). The respiratory variation seen in the IAP tracing is an indirect measurement of abdominal wall compliance [8]. 
Figure I. Intra-abdominal hypertension/abdominal compartment syndrome management algorithm of the World Society of the Abdominal Compartment Syndrome

\section{INTRA-ABDOMINAL HYPERTENSION (IAH) / ABDOMINAL COMPARTMENT SYNDROME (ACS) MANAGEMENT ALGORITHM}

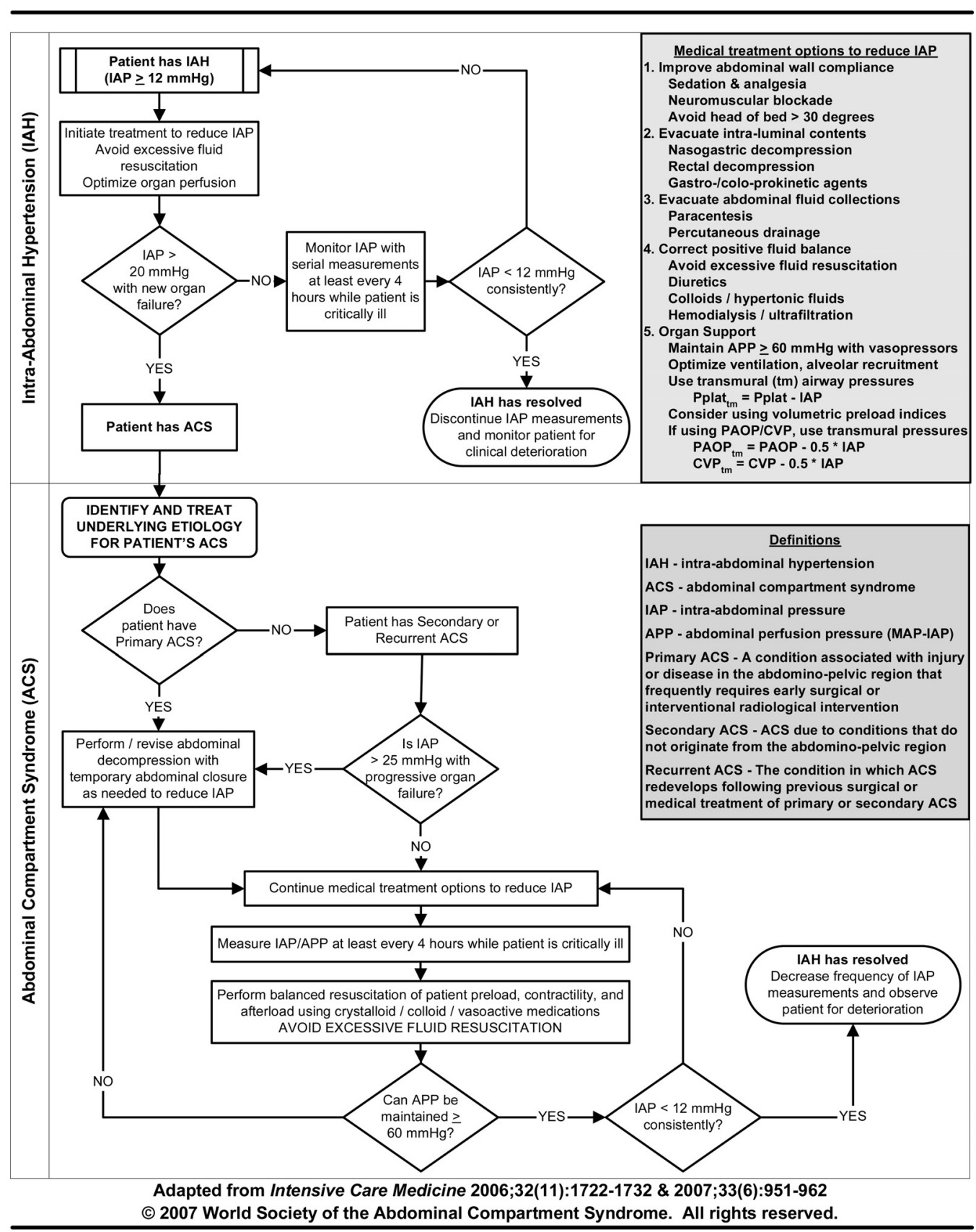

(C) 2007 World Society of the Abdominal Compartment Syndrome. All rights reserved.

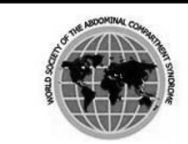

World Society of the Abdominal Compartment Syndrome (WSACS)

ZNA Stuivenberg, Lange Beeldekensstraat 267, B-2060 Antwerpen 6, Belgium

Website: http://www.wsacs.org

ACS, abdominal compartment syndrome; APP, abdominal perfusion pressure; CVP, central venous pressure; $\mathrm{CVP}_{\mathrm{tm}}$, transmural central venous pressure; IAH, intra-abdominal hypertension; IAP, intra-abdominal pressure; MAP, mean arterial pressure; PAOP, pulmonary artery occlusion pressure; $P$ AOP ${ }_{t m}$, transmural pulmonary artery occlusion pressure; Pplat, plateau pressure; Pplat $t_{t m}$, transmural plateau pressure. Adapted from [4,5]. Copyright 2006, 2007, Springer Berlin/Heidelberg. 
Perfusion: Analogous to the widely accepted and clinically used concept of cerebral perfusion pressure [calculated as mean arterial pressure (MAP) minus intracranial pressure (ICP)], abdominal perfusion pressure (calculated as MAP minus IAP) has been proposed as a more accurate predictor of visceral perfusion and a potential endpoint for resuscitation [9]. Although patients with IAH need to be well resuscitated, there is a lot of debate regarding futile crystalloid over-resuscitation and the development of secondary IAH [10].

Measurement: The reference standard for intermittent IAP measurement is via the bladder with a maximal instillation volume of $20-25 \mathrm{~mL}$ of sterile saline. The IAP should be expressed in millimeters of mercury ( $\mathrm{mm} \mathrm{Hg}$ ) and measured at end-expiration in the complete supine position after the clinician ensures that abdominal muscle contractions are absent and that the transducer is zeroed at the level of the midaxillary line. Recent studies have examined the effect of different zero reference and head-of-bed positions on IAP $[11,12]$.

Normal values: Normal IAP is approximately $5-7 \mathrm{~mm} \mathrm{Hg}$ in critically ill adults. IAP may be increased to $12-15 \mathrm{~mm}$ $\mathrm{Hg}$ in postoperative patients. Chronic IAP elevations can be seen in liver cirrhosis with ascites, large ovarian tumors, pregnancy, chronic ambulatory peritoneal dialysis (CAPD), or obesity.

Intra-abdominal hypertension: IAH is defined as a sustained or repeated pathologic elevation of IAP of greater than $12 \mathrm{~mm} \mathrm{Hg}$ [4]. IAH is graded as follows: grade I, IAH of 12-15 mm Hg; grade II, IAH of $16-20 \mathrm{~mm}$ $\mathrm{Hg}$; grade III, IAH of 21-25 mm Hg; and grade IV, IAH of greater than $25 \mathrm{~mm} \mathrm{Hg}$. It should be noted that the IAP ranges associated with these grades have been revised downward in recent years as the detrimental impact of elevated IAP on end-organ function has been recognized. Table 1 lists some risk factors for the development of IAH.

Abdominal compartment syndrome: ACS is defined as a sustained IAP of at least $20 \mathrm{~mm} \mathrm{Hg}$ that is associated with new organ dysfunction/failure.

The WSACS suggests the following classification for IAH: Primary IAH is a condition associated with injury or disease in the abdomino-pelvic region which frequently requires early surgical or radiological intervention. Secondary IAH is a condition that does not originate from the abdomino-pelvic region. Recurrent IAH is a condition in which IAH/ACS redevelops following previous surgical or medical treatment of primary or secondary IAH/ACS.
Table I. Risk factors for the development of intra-abdominal hypertension and abdominal compartment syndrome

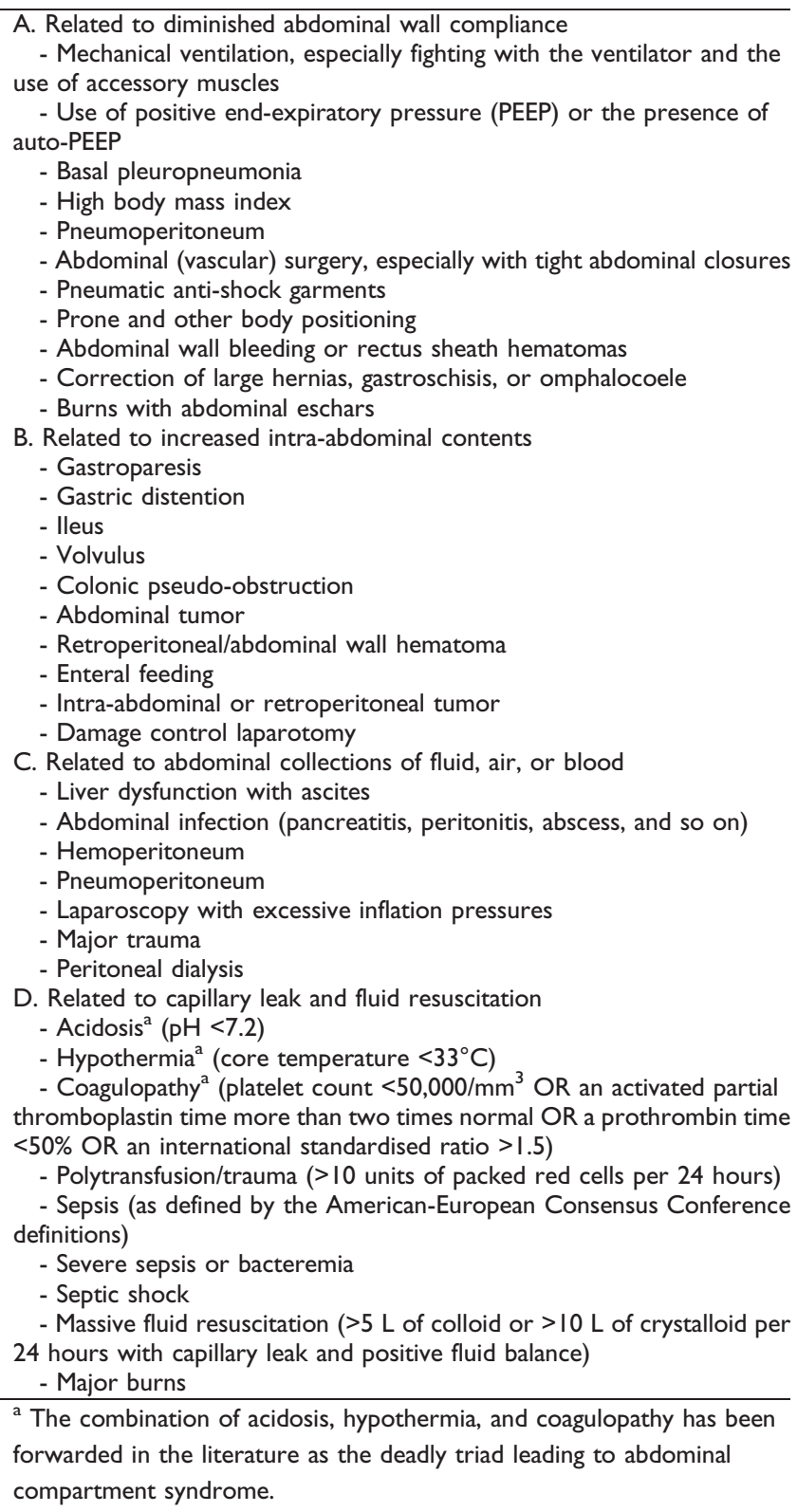

Further classification can be done in relation to the time course of the events: chronic IAH (occurring over the course of months to years) as seen with morbid obesity, intra-abdominal tumor (large ovarian cyst, fibroma, and so on), chronic ascites (liver cirrhosis or CAPD), or pregnancy; in those cases, the abdominal wall adapts progressively during months or years to the increase in IAP and allows time for the body to adapt. Acute IAH is due mainly to trauma or intra-abdominal hemorrhage of any cause and leads to ACS within hours. Subacute IAH is seen with most medical cases in the intensive care unit that lead to IAH within days and results from a 
combination of etiologic factors and predisposing conditions. Hyperacute IAH lasts for only a very short period (seconds or minutes) as with laughing, straining, coughing, sneezing, defecating, or performing physical activity and has no clinical implications.

\section{Implications for clinical practice \\ Organ support}

Figure 2 lists the effects of IAH/ACS on end-organ function [13]. In the paragraphs below, some key points to remember are listed [14].

Figure 2. Impact of increased intra-abdominal pressure on end-organ function

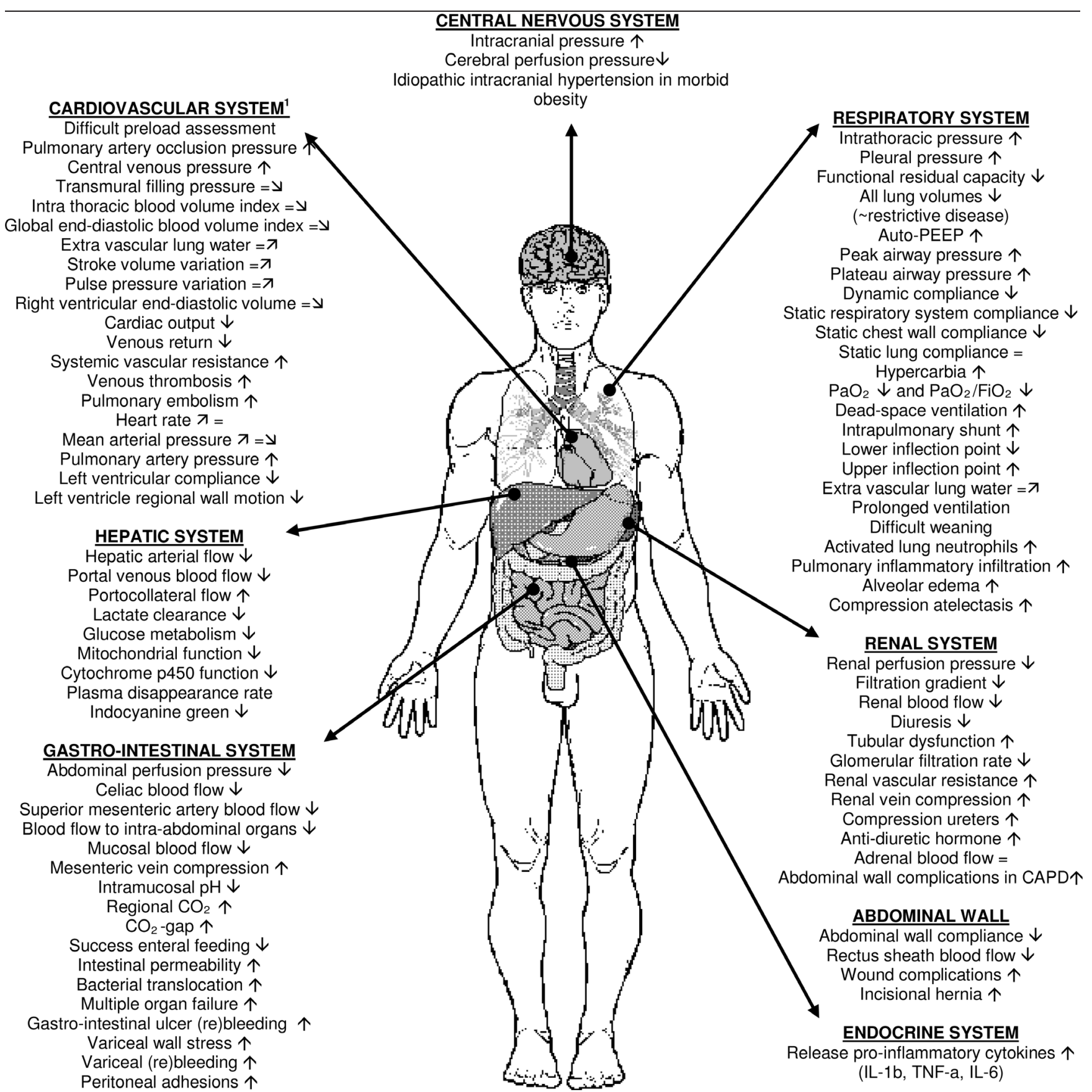

'Cardiovascular effects are exacerbated in case of hypovolemia, hemorrhage, ischemia, and ventilation with high positive end-expiratory pressure (PEEP). CAPD, continuous ambulatory peritoneal dialysis; $\mathrm{FiO}_{2}$, fraction of inspired oxygen; IL, interleukin; $\mathrm{PaO}_{2}$, arterial partial pressure of oxygen; TNF-a, tumor necrosis factor-alpha. 
For the brain [15-17]: IAH/ACS will increase ICP and decrease cerebral perfusion pressure. Because of the interactions between IAP, intrathoracic pressure (ITP), and ICP, accurate monitoring of IAP in head trauma victims with associated abdominal lesions is worthwhile. The presence of increased IAP can be an additional 'extracranial' cause of intracranial hypertension (ICH) in patients with abdominal trauma without overt craniocerebral lesions. Laparoscopy should be avoided in patients with ICH. Obesity causes idiopathic $\mathrm{ICH}$, and weight loss after bariatric surgery is associated with improvements in ICP and symptoms. The direct effects of IAH on neurologic function can be ablated by sternotomy, pericardiotomy, or bilateral pleurotomy [18]. Recently, IAH has been related to ventriculoperitoneal shunt dysfunction [19].

For the heart [20-23]: The clinician must be aware of the polycompartment syndrome and the interactions between ITP, IAP, positive end-expiratory pressure (PEEP), and intracardiac filling pressures. Use transmural filling pressures as a preload estimate, calculated as the end-expiration value minus the ITP: transmural central venous pressure $\left(\mathrm{CVP}_{\mathrm{tm}}\right)=$ end-expiration central venous pressure $\left(\mathrm{CVP}_{\mathrm{ee}}\right)$ - ITP, or transmural pulmonary artery occlusion pressure $\left(\mathrm{PAOP}_{\mathrm{tm}}\right)=$ end-expiration pulmonary artery occlusion pressure $\left(\mathrm{PAOP}_{\mathrm{ee}}\right)-\mathrm{ITP}$. The average abdomino-thoracic transmission is around $50 \%$. A quick estimate of transmural filling pressures can also be obtained by subtracting half of the IAP from the endexpiratory filling pressure, or $\mathrm{CVP}_{\mathrm{tm}}=\mathrm{CVP}_{\mathrm{ee}}-1 / 2 \mathrm{IAP}$ and $\mathrm{PAOP}_{\mathrm{tm}}=\mathrm{PAOP}_{\mathrm{ee}}-1 / 2 \mathrm{IAP}$. Maybe the Surviving Sepsis Campaign guidelines for initial and ongoing resuscitation should be guided toward a $\mathrm{CVP}_{\mathrm{tm}}$ of 8-12 $\mathrm{mm} \mathrm{Hg}$ and a transmural MAP of $65 \mathrm{~mm} \mathrm{Hg}$ to avoid unnecessary over- and under-resuscitation. Use volumetric estimates of preload status to take into account the changing ventricular compliance and elevated ITP: right ventricular end-diastolic volume index or global end-diastolic volume index. Functional hemodynamic parameters such as stroke volume variation or pulse pressure variation, but not systolic pressure variation, should be used to assess volume responsiveness.

For the lungs [24-26]: As a rule of thumb, the best PEEP may be set to counteract IAP whilst at the same time avoiding overinflation of already well-aerated lung regions. The best PEEP $\left(\mathrm{cm} \mathrm{H}_{2} \mathrm{O}\right)=\operatorname{IAP}(\mathrm{mm} \mathrm{Hg})$ to a maximum value of 20 . This holds especially true in the setting of secondary acute respiratory distress syndrome related to abdominal problems (with IAH). In case of ACS with an IAP of greater than $20 \mathrm{~mm} \mathrm{Hg}$, all medical and surgical options to lower IAP and restore end-organ perfusion should be performed. Plateau pressures (Pplat) should be limited to transmural plateau pressures (Pplat ${ }_{\mathrm{tm}}$ ) of below $35 \mathrm{~cm} \mathrm{H}_{2} \mathrm{O}$ : Pplat $\mathrm{tm}_{\mathrm{m}}=$ Pplat $-1 / 2$ IAP. IAH will lead to pulmonary hypertension and increases lung edema in case of capillary leak and fluid overload. Therefore, monitoring extravascular lung water index may be worthwhile.

For the liver [27,28]: Monitor noninvasive hepatosplanchnic perfusion during IAH. Indocyanine green plasma disappearance rate decreases during IAH [29].

For the kidneys [30-32]: Elevated IAP significantly decreases renal artery blood flow and compresses the renal vein, leading to renal dysfunction and failure [33]. Oliguria develops at an IAP of $15 \mathrm{~mm} \mathrm{Hg}$ and anuria at $30 \mathrm{~mm} \mathrm{Hg}$ in the presence of normovolemia and at lower levels of IAP in the patient with hypovolemia or sepsis. Renal perfusion pressure (RPP) and renal filtration gradient have been proposed as key factors in the development of IAP-induced renal failure $(\mathrm{RPP}=\mathrm{MAP}-$ IAP).

Changes in IAP have a greater impact upon renal function and urine production than do changes in

Table 2. Medical treatment options for abdominal compartment syndrome

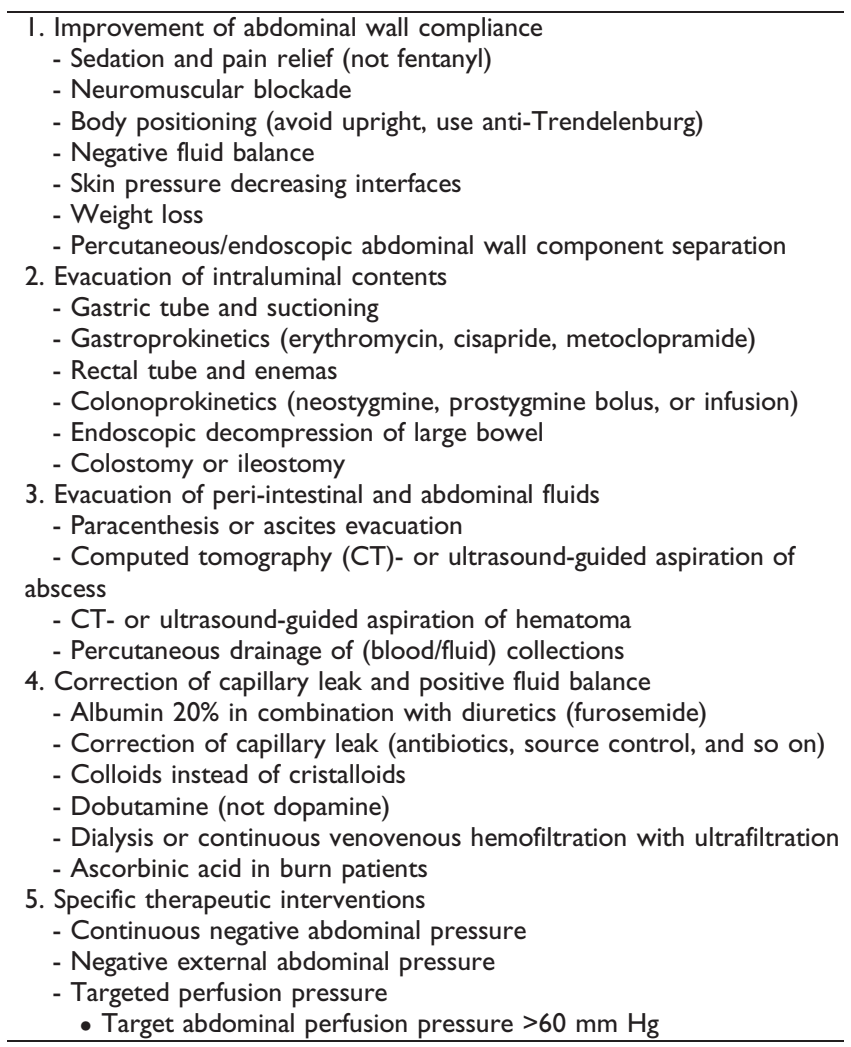


Figure 3. Surgical treatment algorithm for the patient with abdominal compartment syndrome (ACS)

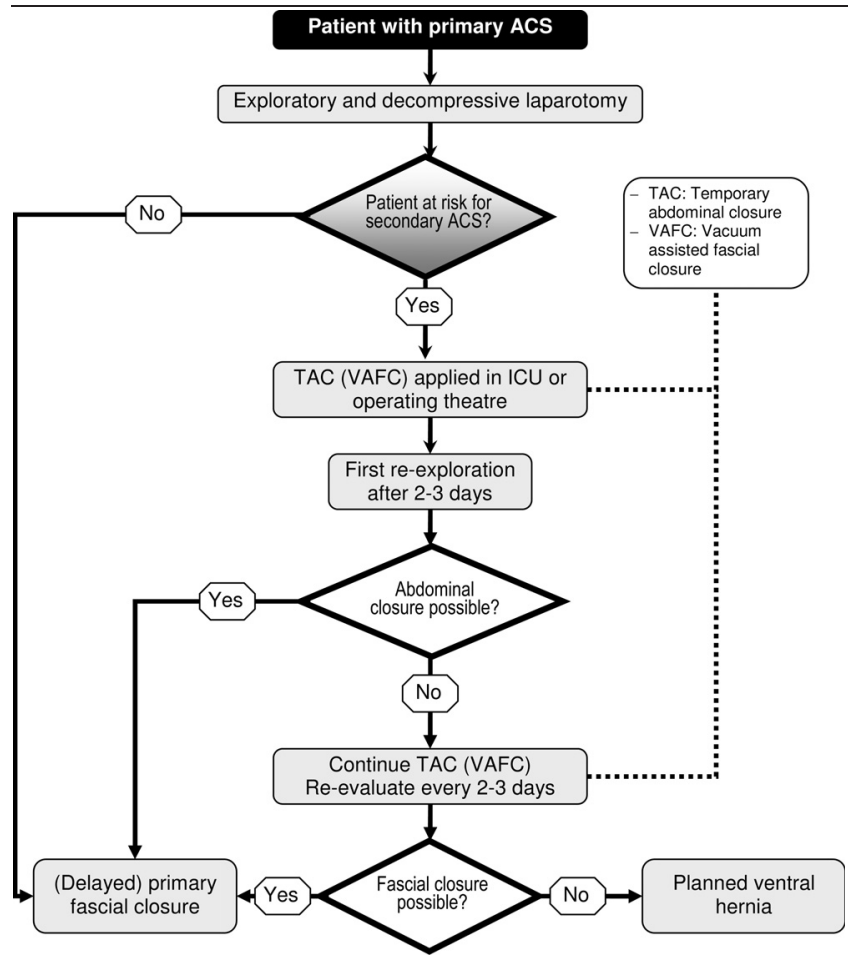

ICU, intensive care unit; TAC, temporary abdominal closure; VAFC, vacuum-assisted fascial closure.

MAP. It should not be surprising, therefore, that decreased renal function, as evidenced by the development of oliguria, is one of the first visible signs of IAH. Therefore, it behooves us as clinicians to be cognizant of the elevated IAP, and its effect on renal function is often the first sign of impending ACS. Recently, Dalfino and colleagues [32] became the first to report a relation between RIFLE (Risk, Injury, Failure, Loss, and End-stage kidney disease) criteria for acute kidney injury and IAH.

\section{Nonsurgical treatment}

Before surgical decompression is considered, less invasive medical treatment options should be optimized. The relation between abdominal contents and IAP is not linear but exponential, and this curve is shifted to the left and upwards when abdominal wall compliance is decreased. Therefore, IAH can be treated by improving abdominal wall compliance and decreasing intraabdominal volume or both. Different medical treatment options have been suggested to decrease IAP; however, it must be noted that, as of today, the evidence regarding these recommendations is scarce and mostly based on case reports and small cohort studies, whereas some evidence is based on speculation and non-evidencebased methods used in ileus and bowel obstruction.
Medical treatment is based on five different mechanisms: (a) improvement of abdominal wall compliance; (b) evacuation of intraluminal contents; (c) evacuation of abdominal fluid collections; (d) correction of capillary leak and positive fluid balance; and (e) specific treatments (see Table 2 for more details).

\section{Surgical treatment}

Decompressive laparotomy is the definitive treatment for ACS [34]. The technique can be invasive (midline laparotomy) or minimally invasive (endoscopic techniques based on subcutaneous anterior abdominal fasciotomy). This intervention results in a laparostomy or open abdomen so that a temporary abdominal closure is needed (moist gauze, towel clip closure, Bogota bag, Wittman patch or zipper, home-made system, or vacuum-assisted closure). Figure 3 shows a surgical treatment algorithm.

\section{Abbreviations}

ACS, abdominal compartment syndrome; CAPD, chronic ambulatory peritoneal dialysis; $\mathrm{CVP}_{\mathrm{ee}}$, endexpiration central venous pressure; $\mathrm{CVP}_{\mathrm{tm}}$, transmural central venous pressure; IAH, intra-abdominal hypertension; IAP, intra-abdominal pressure; ICH, intracranial hypertension; ICP, intracranial pressure; ITP, intrathoracic pressure; MAP, mean arterial pressure; $\mathrm{PAOP}_{e e}$ endexpiration pulmonary artery occlusion pressure; $\mathrm{PAOP}_{\mathrm{tm}}$, transmural pulmonary artery occlusion pressure; PEEP, positive end-expiratory pressure; Pplat, plateau pressures; Pplat $t_{\mathrm{tm}}$, transmural plateau pressure; RIFLE, Risk, Injury, Failure, Loss, and End-stage kidney disease; RPP, renal perfusion pressure; WSACS, World Society of the Abdominal Compartment Syndrome.

\section{Competing interests}

$\mathrm{MM}$ is a past president of the World Society of the Abdominal Compartment Syndrome, is a member of the medical advisory boards of Holtech Medical (Charlottenlund, Denmark), Spiegelberg (Hamburg, Germany), and Pulsion Medical Systems (Munich, Germany), has received royalties from Holtech Medical and Spiegelberg, and holds a patent with Pulsion Medical Systems.

\section{References}

I. Kimball EJ, Rollins MD, Mone MC, Hansen HJ, Baraghoshi GK, Johnston C, Day ES, Jackson PR, Payne M, Barton RG: Survey of intensive care physicians on the recognition and management of intra-abdominal hypertension and abdominal compartment syndrome. Crit Care Med 2006, 34:2340-8.

2. Malbrain ML: Different techniques to measure intra-abdominal pressure (IAP): time for a critical re-appraisal. Intensive Care Med 2004, 30:357-7I.

3. Malbrain ML, De laet I, Cheatham M: Consensus conference definitions and recommendations on intra-abdominal hypertension (IAH) and the abdominal compartment syndrome 
(ACS)-the long road to the final publications, how did we get there? Acta Clin Belg Suppl 2007, 62:44-59.

4. Malbrain ML, Cheatham ML, Kirkpatrick A, Sugrue M, Parr M, De Waele J, Balogh Z, Leppäniemi A, Olvera C, Ivatury R, D'Amours S, Wendon J, Hillman K, Johansson K, Kolkman K, Wilmer A: Results from the International Conference of Experts on Intraabdominal Hypertension and Abdominal Compartment Syndrome. I. Definitions. Intensive Care Med 2006, 32: 1722-32.

5. Cheatham ML, Malbrain ML, Kirkpatrick A, Sugrue M, Parr M, De Waele J, Balogh Z, Leppäniemi A, Olvera C, Ivatury R, D'Amours S, Wendon J, Hillman K, Wilmer A: Results from the International Conference of Experts on Intra-abdominal Hypertension and Abdominal Compartment Syndrome. II. Recommendations. Intensive Care Med 2007, 33:95I-62.

6. De Waele JJ, De laet I, Malbrain ML: Rational intraabdominal pressure monitoring: how to do it? Acta Clin Belg Suppl 2007, 62:16-25.

7. World Society of the Abdominal Compartment Syndrome homepage. [http://www.wsacs.org].

8. Sturini E, Saporito A, Sugrue M, Parr MJ, Bishop G, Braschi A: Respiratory variation of intra-abdominal pressure: indirect indicator of abdominal compliance? Intensive Care Med 2008, 34:1632-7.

9. Cheatham ML, White MW, Sagraves SG, Johnson JL, Block EF: Abdominal perfusion pressure: a superior parameter in the assessment of intra-abdominal hypertension. J Trauma 2000, 49:62I-6; discussion 626-7.

10. Cheatham ML: Intraabdominal pressure monitoring during fluid resuscitation. Curr Opin Crit Care 2008, 14:327-33.

II. De Waele J, De Laet I, De Keulenaer B, Widder S, Kirkpatrick AW, Cresswell AB, Malbrain M, Bodnar Z, Mejia-Mantilla JH, Reis R, Parr M, Schulze R, Compano S, Cheatham M: The effect of different reference transducer positions on intra-abdominal pressure measurement: a multicenter analysis. Intensive Care Med 2008, 34:I299-303.

12. McBeth PB, Zygun DA, Widder S, Cheatham M, Zengerink I, Glowa J, Kirkpatrick AW: Effect of patient positioning on intra-abdominal pressure monitoring. Am J Surg 2007, 193:644-7; discussion 647.

13. Malbrain ML: Is it wise not to think about intraabdominal hypertension in the ICU? Curr Opin Crit Care 2004, I0:132-45.

14. De laet I, Malbrain ML: ICU management of the patient with intra-abdominal hypertension: what to do, when and to whom? Acta Clin Belg Suppl 2007, 62:190-9.

15. De laet I, Citerio G, Malbrain ML: The influence of intraabdominal hypertension on the central nervous system: current insights and clinical recommendations, is it all in the head? Acta Clin Belg Suppl 2007, 62:89-97.

16. Citerio G, Vascotto E, Villa F, Celotti S, Pesenti A: Induced abdominal compartment syndrome increases intracranial pressure in neurotrauma patients: a prospective study. Crit Care Med 200I, 29:1466-7I.

17. Bloomfield GL, Ridings PC, Blocher CR, Marmarou A, Sugerman HJ: Effects of increased intra-abdominal pressure upon intracranial and cerebral perfusion pressure before and after volume expansion. J Trauma 1996, 40:936-4I; discussion 94I-3.

18. Bloomfield GL, Ridings PC, Blocher CR, Marmarou A, Sugerman HJ: A proposed relationship between increased intra-abdominal, intrathoracic, and intracranial pressure. Crit Care Med 1997, 25:496-503.
19. Miele V], Bendok B, Bloomfield SM, Ondra SL, Bailes JE: Ventriculoperitoneal shunt dysfunction in adults secondary to conditions causing a transient increase in intra-abdominal pressure: report of three cases. Neurosurgery 2004, 55:434.

20. Cheatham ML, Malbrain ML: Cardiovascular implications of abdominal compartment syndrome. Acta Clin Belg Suppl 2007, 62:98-II2.

21. Renner J, Gruenewald M, Quaden R, Hanss R, Meybohm P, Scholz J, Bein $B$ : Influence of increased intra-abdominal pressure on fluid responsiveness predicted by pulse pressure variation and stroke volume variation in a porcine model. Crit Care Med 2009, 37:650-8.

22. Gruenewald M, Renner J, Meybohm P, Hocker J, Scholz J, Bein B: Reliability of continuous cardiac output measurement during intra-abdominal hypertension relies on repeated calibrations: an experimental animal study. Crit Care 2008, I 2:RI32.

23. Ridings PC, Bloomfield GL, Blocher CR, Sugerman HJ: Cardiopulmonary effects of raised intra-abdominal pressure before and after intravascular volume expansion. J Trauma 1995, 39: 107|-5.

24. Pelosi $P$, Quintel M, Malbrain ML: Effect of intra-abdominal pressure on respiratory mechanics. Acta Clin Belg Suppl 2007, 62:78-88.

25. Quintel M, Pelosi P, Caironi P, Meinhardt JP, Luecke T, Herrmann P, Taccone P, Rylander C, Valenza F, Carlesso E, Gattinoni L: An increase of abdominal pressure increases pulmonary edema in oleic acid-induced lung injury. Am J Respir Crit Care Med 2004, 169:534-4I.

26. Talmor D, Sarge T, O'Donnell CR, Ritz R, Malhotra A, Lisbon A, Loring $\mathrm{SH}$ : Esophageal and transpulmonary pressures in acute respiratory failure. Crit Care Med 2006, 34:1389-94.

27. Wendon J, Biancofiore G, Auzinger G: Intra-abdominal hypertension and the liver. In Abdominal Compartment Syndrome. Edited by Ivatury R, Cheatham M, Malbrain M, Sugrue M: Georgetown: Landes Bioscience; 2006: 138-43

28. Biancofiore G, Bindi ML, Boldrini A, Consani G, Bisà M, Esposito M, Urbani L, Catalano G, Filipponi F, Mosca F: Intraabdominal pressure in liver transplant recipients: incidence and clinical significance. Transplant Proc 2004, 36:547-9.

29. Michelet P, Roch A, Gainnier M, Sainty JM, Auffray JP, Papazian L: Influence of support on intra-abdominal pressure, hepatic kinetics of indocyanine green and extravascular lung water during prone positioning in patients with ARDS: a randomized crossover study. Crit Care 2005, 9:R25I-7.

30. Sugrue $M$, Hallal A, D'Amours S: Intra-abdominal pressure hypertension and the kidney. In Abdominal Compartment Syndrome. Edited by Ivatury R, Cheatham M, Malbrain M, Sugrue M. Georgetown: Landes Bioscience; 2006: I 19-28.

3I. Sugrue M, Jones F, Deane SA, Bishop G, Bauman A, Hillman K: Intraabdominal hypertension is an independent cause of postoperative renal impairment. Arch Surg 1999, 134:1082-5.

32. Dalfino L, Tullo L, Donadio I, Malcangi V, Brienza N: Intraabdominal hypertension and acute renal failure in critically ill patients. Intensive Care Med 2008, 34:707-I3.

33. Kirkpatrick AW, Colistro R, Laupland KB, Fox DL, Konkin DE, Kock V, Mayo JR, Nicolaou S: Renal arterial resistive index response to intraabdominal hypertension in a porcine model. Crit Care Med 2007, 35:207-13.

34. De Waele JJ, Hoste EA, Malbrain ML: Decompressive laparotomy for abdominal compartment syndrome-a critical analysis. Crit Care 2006, I0:R5I. 